\title{
Discussion to the special issue Supporting the transition of a diversity of students: Developing the "whole student" during and beyond their time at higher education.
}

\author{
Jacques van der Meer ${ }^{1}$ \\ ${ }^{1}$ University of Otago, New Zealand
}

\section{Introduction}

Apart from the current Covid19 context, the higher education sectors across the world have been faced with major challenges over the last few decades (Auerbach et al., 2018; Haggis, 2004), including increased numbers and diversity. Considering the many challenges in higher education, especially the rise of students' mental health issues, I am strongly convinced that education sectors, but in particular the higher education sector, have a societal responsibility to not just focus on students as learners of knowledge and/or professional skills, but to support them in being developed as "whole students". All these challenges also raise a need for research into the broader context to identify how we can better support the diverse student population as they transition into higher education, but also how to prepare them for a positive experience during and beyond their time in higher education.

Overall, it can be said that the contributions to this special issue beneficially addressed some of the main foci to widening the perspectives on diversity related to the transition into higher education. The contribution came from different European countries, including Belgium, Germany, Italy, Sweden, Switzerland, The Netherlands and the United Kingdom.

De Clercq et al. (in this special issue) indicated that environmental characteristics, such as distinctiveness of countries, is often overlooked in research. In this discussion article, therefore, some particular references will also be made to a specific country, New Zealand. This may be of interest and relevant for the particular questions raised in this special issue as focusing on student diversity in educational contexts has been considered important for some time in this country. Aoteraroa New Zealand is a country in the South Pacific colonised by Europeans in the $19^{\text {th }}$ century. In the second part of the $20^{\text {th }}$ century, the focus across the New Zealand education sectors, including higher education, started to develop beyond just a European perspective, and started to focus more on recognition of student diversity. Initially, the main focus was on the indigenous population, the Māori people. In the last few decades of the $20^{\text {th }}$ century, the focus was extended to the Pacific Island people, many of whom migrated to New Zealand from a wide range of different islands in the South Pacific. In the $21^{\text {st }}$ century, the focus on Culturally and Linguistically Diverse (CALD) groups was further extended, and over the last decade also because of the increase of refugees from the Middle East and Asia. Providing some insights from the other end of the world, in quite a different and de-colonised ex-European nation may help European (and other) countries to reflect on their own approaches. 


\section{The whole student}

Considering the main focus of this special issue on the diversity of students' transitioning, the importance of considering multiple aspects and system levels that may impact on this, and the many challenges in the higher education sectors, the approach of developing the "whole student" and related research approaches can provide a way to bring all this together.

Making an argument that developing the "whole student" is beneficial not only for a diversity of students, but also for the higher education institutions and overall society, I believe is very important. However, this is a very complex and broad area that could cover hundreds of pages. In this discussion article, I will touch on some of the key facets related to this, with particular references to the articles in this special issue. Hopefully this may prompt more interest and research, and broader research approaches in this area.

There are different ways to describe "whole student development". I propose describing this as: the development of students' intellectual, emotional, social and well-being capacities, aimed at preparing them for academic success, employability, civic-mindedness and a positive resilient holistic wellbeing future. Holistic wellbeing can be described in many ways. I suggest that this could include physical, mental, social and spiritual aspects. Spirituality could be considered as having a sense that life has meaning and purpose (even when confronted with adversity) and a sense of identity, self-awareness and connectedness with others, nature and the universe.

In the following sections, I will relate the whole student with the results of the special issue, in particular regarding its widened perspective of diversity, its contribution to the $21^{\text {st }}$ century learning and teaching approach and its integration of multi-level and longitudinal research approaches to address the transition to Higher Education.

\section{An expanded notion of diversity to consider the whole student}

Considering the whole student asks for an extended notion of diversity in the literature on Higher Education. Diversity has to be considered at multiple levels, not just related to student backgrounds and characteristics (micro level), but also at the institutional (meso) level and the broader socio-cultural and national (macro) level.

In their article, Baloo et al. (2021) point out that we need to move away from a deficit approach of just focusing on student backgrounds when considering academic achievement. They clarify that only by fully exploring students' differential outcomes at all levels, we can more comprehensively understand the role of student diversity in educational transitions. Messina Dahlberg et al. (in 2021) argue that we have to move away from a deficit approach, and recognise competencies of students, in particular refugee students.

Again, Messina Dahlberg et al. (2021) emphasize the importance and support of diversity at different levels. At a micro level, they say it is very important that first-year students are supported to develop a greater sense of their identity, and to feel that they matter. In their transition and during their first year in higher education, to feel that they matter helps them to develop a sense of belonging, which contributes to their overall wellbeing. Messina Dahlberg et al. also point out that diversity does not just reside in a single individual, but is also situated at a meso (institutional) level. They clarify that an explicit policy focused on equity and diversity is important. As an example of this, in their equity and diversity policy, the University of Otago articulate that it "is committed to equity and diversity and seeks to provide an accessible, inclusive, respectful and welcoming environment in which all students and staff are supported towards achieving their full potential". (University of Otago, n.d.). That policy also further indicates the range of diversity. Considering the New Zealand context, ethnicity comes first, with a particular focus on the importance of the role of the indigenous Māori population. The Pacific Island population is also specifically mentioned. Then other groups are mentioned: students and staff with disability and/or impairment; students who are first in their family to attend university; LGBTIQ 
students and staff; students from low socio-economic backgrounds; students and staff from migrant and/or refugee backgrounds and those whose first language is not English, and women where there are barriers to access and/or success.

Messina Dahlberg et al. (2021) also discuss the importance of the role of the universities in the rites of passage of diverse students as they enter university, especially students of minority groups such as migrant and refugee students. At the University of Otago, in the formal academic convocation (welcoming ceremony) of all first-year students (in the local stadium at the beginning of orientation week), the diverse student groups are explicitly mentioned and it is emphasized that the university will actively support them all in their diversity. This starts the diverse students' population sense that they all matter. At a macro level, ideally there are relevant national policies that entice or force higher education institutions to develop equity and diversity. This is the case in New Zealand with a wide range of policies.

\section{Developing a greater focus on $21^{\text {st }}$ century life-long active learning teaching approaches}

A greater focus on life-long and active learning can contribute significantly to the whole student, in particular their transition into their first year and academic and social integration because it enhances their peer interaction and development of friendships. Braxton et al. (2000) focused in particular on these benefits for students: "active learning course practices may directly influence social integration and indirectly affect subsequent institutional commitment and student departure decisions" (Braxton et al., 2000, p.572).

In their article in this special issue, Willems et al. made a clear argument that a focus on learning strategies may be important. They point at the relevance of learning activities that lead to meaningful learning and more in-depth understanding of the learning content. Active learning approaches indeed can enhance "deep learning" (Haack, 2008). They also emphasize self-regulation. Although their study found that students with deep learning approaches and good self-regulation at the end of secondary education did not necessarily do better in their academic adjustment, I would argue that deep learning and self-regulation may need to be developed explicitly for specific higher education contexts. Active learning approaches by higher education teachers may contribute to this. Self-efficacy can also be considered important in developing life-long learning.

Willems et al. (2021) showed in their research that students' self-efficacy was positively associated with academic adjustment. It had a positive impact on academic achievement, both directly and indirectly, through academic adjustment. They also found that it had a direct positive impact on academic achievement both for students who were enrolled in more academically focused programmes and those who were enrolled in vocational/professional courses.

The importance and the role of self-efficacy was discussed in many other studies in this special issue. With their multifactorial approach, De Clercq et al. (2021) found that self-efficacy beliefs was one of the strongest predictors of academic achievement. In their research Bohndick et al. (2021) also identified the importance of self-efficacy beliefs. In their focus on how differences in the perception of first-year requirements can be explained, they showed that it mostly depended on the individual factors such as self-efficacy and volition. Jenert and Brahm (2021) found in their quantitative study a general decline in students' overall motivation and self-efficacy as well as an increase in study-related anxiety over the first year. However, some students scored high on anxiety despite their high motivation and self-efficacy. They also considered these factors in their qualitative study and found that students who scored high in these constructs generally did well in mastering the challenges of the first year. 


\section{Supporting first-year and ongoing transition through development of learning power and learning disposition skills}

Supporting first-year students in their transition to higher education can be done through many different approaches, and there has been quite some research focussed on this. In this special issue, various authors focused on different aspects.

Van der Zanden et al. (2021) concluded that secondary teachers' practices related to students' social and emotional adjustment across the transition to university, but not to their academic achievement. And they articulated that teachers in secondary education might play a pivotal role in preparing students for university and that their teaching may have a long-term impact on first-year students' social and emotional adjustment.

Bohndick et al. (2021) also make a point for the role of universal interventions to support students. They argue that individual diversity needs to be recognised but institutions need to be careful not to stigmatize particular social groups of students. Focusing on students' experience and response to academic requirements, they advocate for general transparency with regard to the specific demands of the different disciplines and study programmes in order to enable all students to better navigate the firstyear challenges.

De Clercq et al. (2021) focused on differences between institutions or programs that could result in different higher education adjustment experiences. They also investigated the individual and contextual factors that impact on academic achievement. Their findings support the theoretical assumption of the three-level framework of higher education. They show that micro-level characteristics of the transition must be considered but it is necessary to include meso and macro influences/factors. It is important to consider both immediate and more distal environmental settings and how they interact with individual characteristics. Finally, they found that contextual differences predicted about 15 percent of academic achievement, but that this was different depending on students' study programs.

Willems et al. (2021) also considered differences between academic programmes and professional programmes. They found that learning strategies and motivational variables at the end of secondary education were more predictive for students' first-year adjustment in the academic programmes than in professional programmes. They further showed that academic adjustment in the first semester influenced academic achievement more in professional programmes than in academic programmes, even when controlling for students' prior education. As they clearly articulate, students who are more self-regulated are able to actively steer their own learning processes through activities such as planning tasks, monitoring progress, and diagnosing problems.

Considering all the articles, it is clear that there is general agreement that supporting students in their transition into higher education is important and that various issues need to be addressed, including, for example, self-efficacy, motivation, self-regulation and emotional adjustment. I would also argue that this would support students to be effective learners not only in their first year, but depending on the approach, could also benefit the remainder of their time in higher education and beyond.

\section{Enhancing peer interaction}

In the light of research on the important role of social integration in the transition process of first-years students, Jenert and Brahm, included that aspect in their study. Peer interaction is also closely connected to the issue of diversity. Through interacting with other diverse students, they can learn more about diversity, but also learn more about their own identity, and gain other benefits, such as improved communication between students in culturally diverse classes (Keating et al, 2020).

Therefore, developing the whole student could benefit from a greater focus in curricula on developing students inter-relational engagement with other students, and their intercultural competency. This could be done for example by including more group activities during class (all classes, whether lectures, tutorials, workshops, labs etc.) and team/group projects outside of class. This may benefit 
students' development of appreciation of diversity, inter-cultural communication, and overall sense of connectedness and sense of belonging (Deardoff, 2004, 2006, 2009). Einfalt (2020) also specifically identified that it promotes students' transition.

What was really interesting is that the results from Jenert and Brahm's study suggest that when student diversity is taken into account, relationships between personal and contextual variables may not necessarily be predictable. Their qualitative results, for example, showed that peer interaction counted among the factors which were experienced differently by different students. This is also reflected in studies showing that students from more collectivist cultures may benefit more greatly from peer interaction and collaboration. This was also found in my analysis of data from all New Zealand universities related to students' engagement. It was found that the ethnic groups of Māori and Pacific Island students did indeed appreciate this more than other ethnic groups, such as New Zealand European students (van der Meer, 2011).

\section{Integrated multi-level longitudinal research}

In many articles in this special issue, research related to diversity of students' first-year transition reported that ideally, we need to take into account a wide range of variables from the micro, meso and macro levels, and also to cover multi-dimensional aspects. In their study, Bohndick et al. (2021) clearly went beyond student characteristics and also considered social and organisational diversity factors, which they proved had an impact.

It is important to gain holistic knowledge of the complex wide variety of potential factors that may impact on the broad range of diverse student groups in their transition into university. Accordingly, many research approaches need to be used, both quantitative, qualitative and mixed-methods. Jenert and Brahm's study (2021) is a good example. Their study reflects the complexity of interactions between individual and contextual differences. Their mixed method approach provides some good new insights into person-contextual interactions. One of their interesting findings was that there were participant profiles with consistent patterns across self-efficacy, anxiety, and motivation and that students who were assigned to the highly anxious profile were the least self-confident and least motivated. Concerning the links between personal and contextual diversity, their findings showed that students with different profiles at the point of entry coped very differently with the challenges that they encountered in the transition to higher education.

Baloo et al. (2021) also made a great contribution regarding the consideration of different methodologies. They identified that there are significant challenges in how to address differential student outcomes in terms of academic achievements and first-year transition. They argue that the negative focus of many studies on differential outcomes is based on students' deficiencies rather than broader contextual factors. So they provide ideas for far more nuanced analyses of institutional data that can enable universities to take a more proactive approach to monitoring and reducing differences in student success. For example, they point at the importance of interventions to be informed by evidence and identifying whether universal interventions are beneficial for all or may be particularly beneficial for specific student groups. Exploring meso-level variables, in particular, is important, because these variables are under the control of the university. These provide the potential for analysing crossinstitutional data. This is also an argument I made in the analysis of data from all New Zealand universities with regards to the various aspects and benefits of student engagement (van der Meer, 2011).

Baloo et al. (2021) suggested to use different regression techniques. It provides the options to consider what predicts particular outcomes, whether these are predictors related to students before they start university or once they are at university.

At the University of Otago, we made an effort to use multiple regression approaches (both linear and binary logistic regressions) to consider the impact of a first-year intervention on students' first-year academic achievement, first-year retention and also degree completion. We used variables from different levels to find out what predicted the outcomes (van der Meer et al., 2017). The intervention we 
studied was the Peer Assisted Study Sessions programme (PASS). In this co-curricular programme, second or third year undergraduate students facilitate study sessions focused on supporting first-year students to develop study skills, problem solving and working together with other students in parallel to particular courses so that students can learn these skills in a relevant context for them. But the focus is absolutely not on re-teaching content. This programme is based on the US programme called Supplemental Instruction (SI) which was developed in the 1970s with a particular focus on supporting the African American minority who finally were allowed to enter universities as a positive result of the civil rights movement. A lot of research has been done since to study the effectiveness of the SI and PASS interventions, including a systematic review of world-wide research (Dawson et al., 2014). SI was introduced in other countries as a result of massification and related diversity of first-year students. The name PASS, rather than SI, is used in most countries other than the US.

Drawing on effectiveness of PASS/SI research (Dawson et al., 2014), we moved away at Otago from just testing whether involvement in the PASS programme had positive benefits or not. Instead we included a 'dose-response' approach. This concept, based on medical studies, means that we assessed whether the number of PASS sessions attended related to better outcomes. We also controlled for many other contextual factors, for example, students' socio-economic background (which in New Zealand is partly measured by the secondary school students attended). So, many variables related to the different levels, micro level (student characteristics), meso level (university based student support intervention) and macro level (socio-economic context).

The results demonstrated that PASS participation indeed impacted on students' first-year academic achievement, first-year retention, and degree completion (within 6 years), and that the number of PASS sessions attended predicted the level of positive outcomes. And the data also demonstrated that PASS participation contributes to students' success over and above their academic ability as measured by their secondary school results. One of the main reasons that participation likely did not just support their level of achievement in the courses to which their PASS programme was related, but also contributed to retention and especially degree completion, is that a great focus of the programme is to help first-year students develop a range of academic skills, and connectedness with other students. In other words, it actively supports academic and social integration which lots of research indicate is of key importance to student success (see e.g. Braxton et al., 2000; Grillo \& Leist, 2013; Terrion \& Daoust, 2011).

\section{Conclusion}

Based on all the articles in this special issue, and this discussion article, it can be argued that higher education institutions should ideally focus more on the broader perspective of how to support the diversity of students transitioning in their first year in higher education, and move away from fragmented research and deficit approaches. The focus of universities ideally would be to develop the "whole student" in order to support students' overall wellbeing and development of skills both for their time at university and beyond. Considering the universal increase of mental health issues of higher education students over the last decade or so, the major current and future challenging contexts for the younger generations, and the rapidly changing work environment, this is of enhanced importance. This is especially important if universities consider they have a definite responsibility to contribute to their current and future (g)local societies. In consequence, national governments should perhaps consider political initiatives to make this a legal requirement and provide related financial funding. In New Zealand, the tertiary education strategy published recently in November 2020, the current government has included that "Wellbeing is fundamentally entwined with learning, and needs to be a goal through all parts of our education system" (NZ Ministry of Education, n.d.)

To achieve many of the goals related to the whole student development, it is also important for governments to invest in broadly skilled educators so that they can meet the diverse and changing needs of students transitioning into higher education. Furthermore ongoing longitudinal research evidence needs to be used to inform effective teaching and interventions to support the academic and wellbeing 
success of the diversity of students. In the NZ 2020 tertiary education strategy, all this is explicitly articulated, including that, "New Zealand needs an education and training system that prepares learners/ākonga for a changing world and the future of work", and also the need to "Develop staff capabilities to support teaching and learning practices that value languages, cultures and identities" (NZ Ministry of Education, n.d.).

Developing the whole student also contributes to the United Nations objective of the Sustainable Development Goals. That is to ensure that "all learners, by 2030, acquire the knowledge and skills needed to promote sustainable development, including, among others, through education for sustainable development and sustainable lifestyles, human rights, gender equality, promotion of a culture of peace and non-violence, global citizenship and appreciation of cultural diversity and culture's contribution to sustainable development" (cited in Sala et al., 2020, p.13). To achieve these goals, it is important to promote well-being, provide inclusive and equitable quality education and promote lifelong learning skills and opportunities (Bebbington \& Unerman, 2018). The recently developed LifeComp framework created by the European Union (Sala et al., 2020) can play an important part in supporting the different education sectors to make positive changes in their education contexts, including the higher education context.

\section{Citations to this special issue}

Balloo, K. et Winstone, N.E. (2021). A primer on gathering and analysing multi-level quantitative evidence for differential student outcomes in higher education, Frontline Learning Research, 9(2), 121-144.https://doi.org/10.14786/flr.v9i2.675

Bohndick C., Bosse, E. Jänsch V.K. et Barnat, M. (2021). How Different Diversity Factors Affect the Perception of First-Year Requirements in Higher Education, Frontline Learning Research, 9(2),78-95. https://doi.org/10.14786/flr.v9i2.667

De Clerq, M., Galand, B., Hospel, V. et Frenay M. (2021). Bridging contextual and individual factors of academic achievement: a multi-level analysis of diversity in the transition to higher education, Frontline Learning Research, 9(2), 96-120. https://doi.org/10.14786/flr.v9i2.671

De Clerq M., Jansen E., Brahm T.et Bosse E. (2021), From Micro to Macro: Widening the Investigation of Diversity in the Transition to Higher Education Frontline Learning Research, 9(2), 1-8. https://doi.org/10.14786/flr.v9i2.783

Jenert, T. et Brahm, T. (2021). The interplay of personal and contextual diversity during the first year at Higher Education: Combining a quantitative and a qualitative approach, Frontline Learning Research, 9(2),50-77. https://doi.org/10.14786/flr.v9i2.669

Messina Dahlberg, G., Vigmo, S. et Surian A. (2021). Widening participation? (Re)searching institutional pathways in higher education for migrant students - The cases of Sweden and Italy, Frontline Learning Research, 9(2), 145-169 https://doi.org/10.14786/flr.v9i2.655

Van der Zanden, P.J.A.C., Denessen, E., Cillessen A.H.N. et Meijer, P.C. (2021). Relationships between teacher practices in secondary education and first-year students' adjustment and academic achievement, Frontline Learning Research, 9(2), 9-27. https://doi.org/10.14786/flr.v9i2.665

Willems, J., van Daal, T., van Petegem, P., Coertjens, L et Donche, V. (2021). Predicting freshmen's academic adjustment and subsequent achievement: differences between academic and professional higher education contexts, Frontline Learning Research, 9(2), 28-49. https://doi.org/10.14786/flr.v9i2.647 


\section{References}

Auerbach, R. P., Mortier, P., Bruffaerts, R., Alonso, J., Benjet, C., Cuijpers, P., Demyttenaere, K., Ebert, D. D., Green, J. G., Hasking, P., Murray, E., Nock, M. K., Pinder-Amaker, S., Sampson, N. A., Stein, D. J., Vilagut, G., Zaslavsky, A. M., Kessler, R. C., \& WHO WMH-ICS Collaborators (2018). WHO World Mental Health Surveys International College Student Project: Prevalence and distribution of mental disorders. Journal of Abnormal Psychology, 127(7), 623-638.

Bebbington, J., \& Unerman, J. (2018). Achieving the United Nations sustainable development goals. Accounting, Auditing \& Accountability Journal, 31(1), .

Braxton, J. M., Milem, J. F., \& Sullivan, A. S. (2000). The influence of active learning on the college student departure process: Toward a revision of Tinto's theory. The Journal of Higher Education, 71(5), 569590.

Caena, F., (2019) Developing a European Framework for the Personal, Social \& Learning to Learn Key Competence (LifEComp). Literature Review \& Analysis of Frameworks. Luxembourg: Publications Office of the European Union.

Dawson, P., van der Meer, J., Skalicky, J., \& Cowley, K. (2014). On the effectiveness of supplemental instruction: A systematic review of supplemental instruction and peer-assisted study sessions literature between 2001 and 2010. Review of Educational Research, 84(4), 609-639.

Deardorff, D. K. (2006). Identification and assessment of intercultural competence as a student outcome of internationalization. Journal of Studies in International Education, 10(3), 241-266.

Deardorff, D. K. (2009). Exploring interculturally competent teaching in social sciences classrooms. Enhancing Learning in the Social Sciences, 2(1), 1-18.

Deardorff, D. K. (2004). In search of intercultural competence. International Educator, 13(2), 13-15.

Einfalt, J. (2020). Let's talk about transcultural learning: using peer-to-peer interaction to promote transition and intercultural competency in university students. Journal of Academic Language \& Learning 14(2), 20-39.

Grillo, M. C., \& Leist, C. W. (2013). Academic support as a predictor of retention to graduation: New insights on the role of tutoring, learning assistance, and supplemental instruction. Journal of College Student Retention: Research, Theory \& Practice, 15(3), 387-408.

Haack, K. (2008). UN studies and the curriculum as active learning tool. International Studies Perspectives, 9(4), 395-410.

Haggis, T. (2004). Meaning, identity and 'motivation': expanding what matters in understanding learning in higher education?. Studies in Higher Education, 29(3), 335-352.

Keating, M, Rixon, A., \& Perenyi, A. (2020). Deepening a sense of belonging: A LAS faculty collaboration to build inclusive teaching. Journal of Academic Language \& Learning 14(2), 40-56.

NZ Ministry of Education. (n.d.). The Statement of National Education and Learning Priorities (NELP) and the Tertiary Education Strategy (TES). Retrieved from https://www.education.govt.nz/ourwork/overall-strategies-and-policies/the-statement-of-national-education-and-learning-priorities-nelpand-the-tertiary-education-strategy-tes

Sala, A., Punie, Y., Garkov, V., \& Cabrera Giraldez, M. (2020). LifeComp: The European Framework for Personal, Social and Learning to Learn Key Competence. Luxembourg: Publications Office of the European Union. Retrieved from: https://publications.jrc.ec.europa.eu/repository/bitstream/JRC120911/lcreport_290620-online.pdf

Terrion, J. L., \& Daoust, J. L. (2011). Assessing the impact of supplemental instruction on the retention of undergraduate students after controlling for motivation. Journal of College Student Retention: Research, Theory \& Practice, 13(3), 311-327.

University of Otago, (n.d.). Equity and Diversity Policy - Kaupapa Here Ararau Tōkeke. Retrieved from: https://www.otago.ac.nz/administration/policies/otago666398.html 
van der Meer, J. (2011). Māori and Pasifika students' academic engagement: What can institutions learn from the AUSSE data? In A. Radloff (Ed.), Student engagement in New Zealand's universities (pp. 1-10). Melbourne: Australian Council for Educational Research.

van der Meer, J., Wass, R., Scott, S., \& Kokaua, J. (2017). Entry characteristics and participation in a peer learning program as predictors of first-year students' achievement, retention, and degree completion. AERA Open, 3(3). 